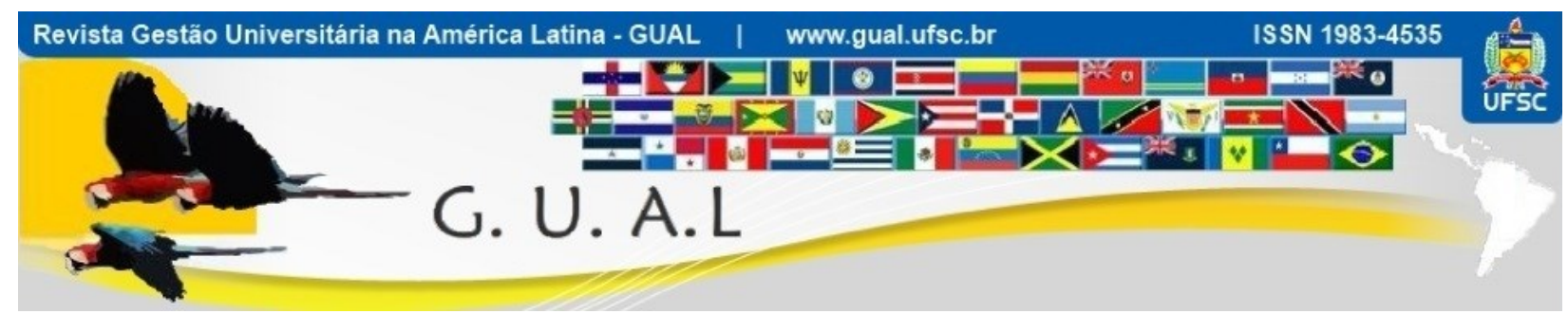

DOI: http://dx.doi.org/10.5007/1983-4535.2019v12n1p162

\title{
AVALIAÇÃO DA EVOLUÇÃO DO ÍNDICE GERAL DE CURSOS - IGC DAS INSTITUIÇÕES DE ENSINO SUPERIOR DE SANTA CATARINA
}

\section{EVALUATION OF THE EVOLUTION OF THE IGC OF SANTA CATARINA'S HIGHER EDUCATION INSTITUTIONS}

Cleber Cervi, Mestre

https://orcid.org/0000-0002-3115-5078

clebercervi@hotmail.com

Universidade Federal do Rio Grande do Sul | Escola de Administração. Programa de Pós-graduação em Administração Porto Alegre | Rio Grande do Sul | Brasil

Adriane Cervi Blümke, Doutora https://orcid.org/0000-0002-8731-1893 adriblumke@yahoo.com.br

Universidade Federal de Santa Maria | Departamento de Alimentos e Nutrição Santa Maria | Rio Grande do Sul | Brasil

Recebido em 30/janeiro/2018

Aprovado em 03/setembro/2018

Publicado em 02/janeiro/2019

Sistema de Avaliação: Double Blind Review 


\title{
RESUMO
}

A competitividade no setor de ensino faz com que as IES necessitem estar atentas à qualidade do serviço que oferecem, objetivando a manutenção e conquista de novos alunos, parceiros ou investidores. Para muitos alunos, a imagem da instituição e sua qualidade percebida são os principais critérios na escolha de uma IES e isso é transmitido, muitas vezes, através da mídia que publica rankings. Como a maioria dos rankings e indicadores levam em conta o conceito IGC os gestores de IES devem estar atentos a ele, procurando estratégias para melhorá-lo, pois serão os responsáveis por transmitir a qualidade da IES e dos cursos. Desta forma, este trabalho busca avaliar a evolução do IGC nas IES de Santa Catarina no período de 2007 a 2014; avaliando se há diferença na qualidade entre IES públicas e privadas, bem como entre as modalidades de organização acadêmica, a saber, Universidade, Centro Universitário, Faculdade e Instituto Federal, com o intuito de verificar se a divulgação de tais indicadores serve, realmente, como incentivador da melhoria da qualidade das IES, tal como proposto pelo MEC. Através dos dados disponíveis no sistema e-MEC e com o auxílio de testes estatísticos é possível concluir que (1) a evolução do IGC foi marginalmente significativa no período analisado; (2) as universidades possuem IGC superior às faculdades em apenas três períodos analisados; (3) as IES públicas possuem IGC superior das IES privadas.

Palavras-chave: IGC. Indicadores de Qualidade. Instituição de Ensino Superior.

\begin{abstract}
The competitiveness in the education sector makes Higher Education Institution (HEI) to be attentive to the quality of service they offer, aiming to maintain and win new students, partners or investors. For many students, the institution's image and its perceived quality are the main criteria in choosing an HEI and it is transmitted, often, through the media that publishes rankings. Most rankings and indicators take into account the concepts of General Index of Courses - IGC, so HEI's managers should be aware of them, looking for strategies to improve them, as they will be responsible for conveying the quality of HEIs and course. Thus, this study sought to determine the evolution of IGC of the Santa Catarina's HEI from 2007 to 2014 and if has difference in the quality of public and private HEI, as well as to evaluate the difference between types of academic organization - namely university, university centers, colleges and federal institutes, in order to examine whether disclosure of such indicators really serves as a promoter of improvement in the quality of the HEI. Using data from the EMEC system and with the help of statistical techniques it's possible to conclude that (1) the evolution of the IGC was marginally significant in the analyzed period, (2) the universities have higher IGC than colleges only in three analyzed years, (3) the public's HEI are superior of private's HEI.
\end{abstract}

Keywords: IGC. Quality Indicators. Higher Education Institution. 


\section{INTRODUÇÃO}

A expansão do ensino superior nos últimos anos no Brasil é evidente. De acordo com dados do senso da educação superior MEC (2018) o Brasil possui 2.364 Instituições de Ensino Superior (IES). O estado de Santa Catarina conta, atualmente, com 13 universidades, 12 centros universitários, 94 faculdades, uma escola de governo, uma instituição especialmente credenciada para oferta de cursos lato sensu e dois institutos federais, totalizando 123 IES ativas. Dessas, 9 são públicas e as outras 114 são privadas. Porém, o desenvolvimento exponencial da educação superior iniciou já na década de 90 devido flexibilização da legislação (BARREYRO, 2008). Para Lourenço e Knop (2011) o crescimento na educação superior pode ser explicado por vários fatores como o aumento de matrículas no ensino médio, a flexibilização promovida pelo Ministério da Educação (MEC) nos critérios para abertura de novos cursos e o reconhecimento da relação entre qualificação e empregabilidade.

A nova legislação permitiu a criação de instituições com menores custos o que proporcionou um aumento no sistema e, consequentemente, acirrou a competição entre as IES, principalmente no setor privado (BARREYRO, 2008; LOURENÇO; KNOP, 2011). Tal competição é evidenciada com a expansão da publicidade no setor, resultando em divulgação crescente das IES nos meios de comunicação.

Como forma de organizar o setor, permitindo a comparação entre IES, o MEC desenvolveu uma série de indicadores que permitem avaliar e comparar a qualidade de cada instituição e cada curso. Atualmente, o Sistema Nacional de Avaliação da Educação Superior (SINAES), implantado pelo Ministério da Educação em 2004, é responsável por avaliar a qualidade do ensino superior no País. Um dos objetivos do SINAES é melhorar a qualidade da educação superior (INEP, 2017). Dentre os principais indicadores de qualidade que o SINAES utiliza para determinar a qualidade das Instituições de Ensino Superior está o Índice Geral de Curso (IGC). A divulgação deste indicador permite aos gestores de IES maior conhecimento sobre sua instituição e sobre os concorrentes. Nesta perspectiva, os indicadores de avaliação de cursos e de Instituições desenvolvidos pelo MEC atuaram como um regulador mercadológico e midiático (BARREYRO, 2004), pois sua forma simples de interpretação através de conceitos ou notas, facilita a comparação e muitas IES utilizam as notas de suas avaliações para indicar ao mercado a sua qualidade e a qualidade de seus cursos. 
Com o grande número de IES e com a competitividade atual do setor, a qualidade do serviço deve sobressair para que seja possível manter e atrair novos alunos, investidores e parceiros. Isso exige medidas efetivas, primeiro para monitorar os indicadores de qualidade que o setor oferece e, segundo, para desenvolver melhorias com o objetivo de aumentar a qualidade da IES. A partir disso, os gestores de IES precisam mudar a forma de ver o setor educacional, percebendo a necessidade de uma gestão mais profissional, com foco para o mercado (BASSO; ANTONI, 2013). Essa necessidade, no entanto, não é exclusiva das IES privadas, pois as IES públicas também competem, entre si e com as IES privadas, por projetos, alunos, prestígio e por recursos (GORDIANO; PEÑALOZA; QUEZADO, 2012).

Sabe-se que qualidade em serviços é um conceito amplo e que a mensuração da qualidade em serviços envolve várias dimensões (PARASURAMAN, ZEITHAML e BERRY, 1988). Porém, esta pesquisa utiliza como critério de mensuração da qualidade os indicadores elaborados e apresentados pelo Ministério da Educação que têm por objetivo avaliar a qualidade das IES (SOBRINHO, 2008) a partir de uma série de dimensões específicas.

Este trabalho não tem por objetivo julgar se esses índices medem a verdadeira qualidade da IES, nem é pretensão desta pesquisa aprofundar o conceito de qualidade em instituições de ensino superior, mas sim observar como os indicadores de qualidade elaborados pelo MEC se comportaram após sua primeira divulgação. Afinal, os indicadores tornam o conceito de qualidade menos subjetivo, permitindo uma identificação objetiva e mensurável, sendo possível a comparação entre as várias IES (SOBRINHO, 2008).

Desta forma, esta pesquisa analisa se houve melhoria no conceito IGC das IES de Santa Catarina desde a sua primeira divulgação em 2007 e se há diferença na evolução dos indicadores entre tipo de organização administrativa (universidade, centro universitário, faculdade e instituto federal) e entre IES públicas e privadas. Tal objetivo surge da necessidade de (i) verificar se a divulgação destes indicadores cumpre o papel, proposto pelo MEC, de melhorar a educação superior, e (ii) analisar o comportamento do IGC após sua primeira divulgação. Para isso, o trabalho seguirá apresentando a revisão dos principais conceitos utilizados na pesquisa. Na sequência descreve-se como se procedeu com a coleta de dados e, após, apresenta-se os resultados da pesquisa. Na conclusão encerra-se com sugestões para pesquisas futuras. 


\section{REFERENCIAL TEÓRICO}

\subsection{QUALIDADE EM INSTITUIÇÕES DE ENSINO SUPERIOR}

Em um contexto de forte concorrência as IES lançam-se ao mercado para atrair novos alunos para a manutenção de seus cursos. Este fenômeno é ainda mais visível, em instituições privadas, pois estas têm no pagamento de mensalidades a principal fonte de recursos para a sobrevivência. Neste cenário, a concorrência fica ainda mais acirrada e, cada vez mais, a qualidade se torna o grande diferencial para manter e atrair novos clientes. Qualidade dos cursos, dos serviços prestados, das instalações e dos funcionários (técnicos e professores) são características que estão presentes na maioria das campanhas de marketing das IES.

Harvey e Green (1993) consideram qualidade como um conceito relativo: relativo à pessoa que usa o termo e à circunstância que o termo é utilizado. De acordo com essa ideia, qualidade pode ter um significado diferente, dependendo de cada pessoa e da situação que ela é utilizada. Em IES o termo qualidade também sofre adaptações dependendo de quem é o consumidor: governo, alunos, comunidade, fornecedores, empregadores, etc. Cada agente possui necessidades e objetivos distintos para avaliar a qualidade.

Como forma de unificar alguns conceitos e também atendendo ao que determinava a Lei de Diretrizes e Bases da Educação Nacional (BRASIL, 1996), o governo elaborou indicadores de qualidade. Estes indicadores buscam diminuir a subjetividade em relação a como a qualidade de uma IES é atribuída, pois é possível realizar a comparação de cursos e de IES, a partir das adequações aos critérios estabelecidos pelo MEC. Sobrinho (2008) acredita que, dessa forma, a qualidade deixa de ser um conceito relativo e passa a ser livre de contextos ou interpretações subjetivas, pois é identificável objetivamente, mensurável e enquadrada em escalas comparativas.

A necessidade de adaptação às exigências do mercado é uma polêmica que há muito ronda o serviço educacional (TOMASSINI; AQUINO; CARVALHO, 2008), mas, recentemente as IES têm tomado consciência da concorrência no ensino superior e da necessidade de maior controle gerencial para superá-la (TURETA et al, 2007). Afinal, Friga, Bettis e Sullivan (2004) chamam atenção para o fato de o mundo globalizado exigir maior rigor e visão mais competitiva das IES. Tomassini, Aquino e Carvalho (2008) afirmam que os mecanismos de avaliação do ensino superior utilizados atualmente pelo MEC são um reconhecimento do imperativo mercadológico que ronda o setor. 
Uma das estratégias das IES são campanhas midiáticas em jornais, revistas, televisão, etc. Muitas IES utilizam as notas do ENADE, do IGC e dos rankings particulares (ex: Guia do Estudante) nessas campanhas publicitárias para divulgar a qualidade de seus cursos, com o objetivo de conquistar mais alunos e mais espaço no mercado. Alves (2009) demonstra em seu estudo que algumas das maiores universidades brasileiras utilizam a nota do ENADE para atestar sua qualidade e diferenciarem-se dos concorrentes. Nesta competição, instituições com notas superiores no ENADE e no IGC muitas vezes saem na frente, já que utilizam estas notas como estratégia de marketing, justificando, inclusive, preços de mensalidades mais elevados devido a qualidade atestada (qualificação do corpo docente, da infraestrutura, etc.).

Com o objetivo de dar subsídios para que gestores e coordenadores de cursos de IES saibam os aspectos que precisam dedicar mais atenção, alguns pesquisadores têm se dedicado a estudar o que afeta a qualidade percebida nas IES e a tomada de decisão dos alunos. Lourenço e Knopp (2011) pesquisaram a qualidade de uma IES vista pela ótica do aluno, identificando aspectos bem avaliados pelos mesmos e aspectos que merecem aperfeiçoamento. Mainardes e Domingues (2011) identificaram que para os alunos os atributos de melhor desempenho na percepção de qualidade das IES são os relacionados à imagem da IES na comunidade, à inovação e ao desenvolvimento de novos cursos. Já Aléssio, Domingues e Scarpin (2010) concluíram que os alunos buscam por tradição e status na hora da escolha. Soares e Milan (2008) atestam que a qualidade e o prestígio da instituição são critérios usados pelos alunos na hora de tomar a decisão entre qual IES estudar. Percebe-se que a maioria destes aspectos é verificada pelo sistema atual de avaliação da educação superior.

Como a qualidade é uma comparação geral entre expectativas e percepções (PARASURAMAN, ZEITHAML e BERRY, 1985), destaca-se a necessidade da IES ser reconhecida pela sociedade. Além de outros aspectos, a qualidade total percebida pelos clientes é influenciada pela imagem ou marca da instituição, que serve como "filtro" na percepção da qualidade. Portanto, não basta ter qualidade é importante que o público perceba essa qualidade, afinal para qualquer negócio o que vale é a qualidade percebida pelo cliente (GRÖNROOS, 2009). Desta forma, o conceito no IGC pode influenciar a imagem de uma instituição perante a sociedade, ou seja, quanto maiores os índices, maior poderá ser a qualidade percebida pelo aluno. 
Em concordância com a importância da nota no IGC alguns pesquisadores buscam encontrar variáveis que podem afetar positivamente a nota do ENADE, dando subsídio aos gestores e coordenadores de cursos de IES para a tomada de decisão. Por exemplo, Cruz, Spinola e Freitas Junior (2009) comprovaram que há correlação positiva entre o percentual de disciplinas de raciocínio quantitativo e o desempenho dos alunos do curso no ENADE. Silva et al (2012) comprovaram que a existência de uma página eletrônica para manter vínculo com os egressos não influencia o IGC.

Independente das visões contrárias sobre a essência do sistema de avaliação e, principalmente, os questionamentos moral e ético que surgem com tal assunto, é fundamental para as instituições de ensino superior pensarem no sistema de avaliação como divulgação da qualidade de seus cursos e instituição e, ainda, propulsor da imagem institucional. Resta saber, portanto, se a divulgação do IGC pelo MEC tem surtido efeito no aumento da qualidade das IES.

\subsection{AVALIAÇÃO DE INSTITUIÇÕES DE EDUCAÇÃO SUPERIOR}

O sistema de avaliação das IES no Brasil passou por um processo de ações, reações e adaptações ao longo dos anos até se transformar no Sistema Nacional de Avaliação da Educação Superior - SINAES, implantado em 2004 e praticado atualmente. Para Barreyro (2008) o assunto avaliação da educação superior não é recente, sendo que na década de 1980 já era tradado com o Programa de Avaliação da Reforma Universitária (PARU) e, após, na década de 1990 com o Programa de Avaliação Institucional das Universidades Brasileiras (PAIUB). Em 1997, com o objetivo de avaliar e regular a educação superior, foi instituído o Exame Nacional de Cursos (ENC), que ficou conhecido como "Provão".

O "provão" passou por momentos de tensões e foi duramente criticado, pois sua classificação em conceitos (A, B, C, D e E) permitia a construção de rankings, o que, para alguns, dava ao ensino um caráter mercadológico (BARREYRO, 2004 e 2008). Porém, essa fórmula o consolidou no cenário nacional, já que permitia comunicação "nos próprios códigos e linguajar da publicidade e do marketing" (BARREYRO, 2004, p. 41). Nessa linha, Barreyro (2008) afirma que com o crescimento exponencial no setor educacional iniciado na década de 90, o "provão" serviu como um regulador do mercado. Muitos cursos, de universidades públicas e privadas, utilizavam a nota do provão como uma estratégia de marketing e publicavam sua colocação no ranking como sinônimo de qualidade (BARREYRO, 2008). 
Para Verhine (2015, p. 607) a Lei de Diretrizes e Bases da Educação Nacional (BRASIL, 1996) "consolidou a necessidade dos processos de avaliação". Com base nisso, o Plano Nacional de Educação - PNE, criado pela Lei 10.172 de 2001, determinou que a União instituiria o Sistema Nacional de Avaliação e estabeleceria os mecanismos necessários para o acompanhamento das metas do PNE. "Com base nessas determinações legais e considerando também o relatório produzido por uma Comissão Especial criada em 2003" institui-se o Sistema Nacional de Avaliação da Educação Superior - SINAES (VERHINE, 2015, p. 607). O SINAES foi sancionado pela lei $\mathrm{n}^{\circ} 10.861$, de 14 de abril de 2004, com o objetivo de assegurar processo nacional de avaliação das instituições de educação superior, dos cursos de graduação e do desempenho acadêmico de seus estudantes. O SINAES tinha como finalidade, dentre outras, a melhoria da qualidade da educação superior. O SINAES é formado, hoje, por três componentes principais: a avaliação das instituições, dos cursos e do desempenho dos estudantes. O SINAES avalia todos os aspectos que giram em torno do ensino, da pesquisa, da extensão, da responsabilidade social, do desempenho dos alunos, da gestão da instituição, do corpo docente, das instalações físicas e outros aspectos. Os processos avaliativos são coordenados e supervisionados pela Comissão Nacional de Avaliação da Educação Superior (CONAES) e a operacionalização é de responsabilidade do Instituto Nacional de Estudos e Pesquisas Educacionais Anísio Teixeira - INEP (INEP, 2017).

A avaliação das instituições se dá pela avaliação interna e externa e se baseia em dimensões como: missão e PDI; política para o ensino, a pesquisa, a pós-graduação e a extensão; responsabilidade social da IES; comunicação com a sociedade; as políticas de pessoal, as carreiras do corpo docente e técnico-administrativo; organização de gestão da IES; infraestrutura física; planejamento de avaliação; políticas de atendimento aos estudantes; e sustentabilidade financeira. Já a avaliação dos cursos é realizada com base em três dimensões: organização didático-pedagógico, perfil do corpo docente e instalações físicas. Por fim, a avaliação dos estudantes se dá através do Exame Nacional de Desempenho de Estudantes (ENADE), que é aplicado periodicamente aos concluintes dos cursos de graduação. O objetivo do ENADE é avaliar o desempenho dos estudantes com relação aos conteúdos programáticos previstos nas diretrizes curriculares dos cursos de graduação, o desenvolvimento de competências e habilidades necessárias ao aprofundamento da formação geral e profissional, e o nível de atualização dos estudantes com relação à realidade brasileira e mundial. (INEP, 2017). 
Na edição do ENADE de 2008, o MEC-INEP divulgou junto com a nota do ENADE dois novos índices: o Conceito Preliminar de Curso (CPC), instituído pela Portaria Normativa $\mathrm{n}^{\mathrm{0}} 4$ de 05 de agosto de 2008, e o Índice Geral de Curso (IGC), instituído pela portaria Normativa $\mathrm{n}^{\circ} 12$, de 05 de setembro de 2008. O cálculo do IGC leva em conta três aspectos: (1) a média dos últimos três anos do CPC dos cursos avaliados da instituição, ponderado pelo número de matrículas em cada um dos cursos computados, (2) a média dos conceitos de avaliação dos programas de pós-graduação stricto sensu atribuídos pela CAPES na última avaliação disponível, convertida em escala padrão e ponderada pelo número de matrículas em cada programa de pós-graduação, (3) distribuição dos estudantes entre os diferentes níveis de ensino (graduação ou pós graduação stricto sensu), excluindo as informações do item 2 para IES que não oferecem pós-graduação stricto sensu (INEP, 2017). O IGC é usado como referencial norteador das comissões de avaliação institucional, para a avaliação do ato de Recredenciamento Institucional. De acordo com informações disponíveis no site do INEP o IGC é um indicador de qualidade de instituições de educação superior e seu resultado é expresso em valores contínuos (de 0 a 500) e em faixas (de 1 a 5).

Percebe-se que o CPC é um componente fundamental do IGC. O CPC é elaborado com o objetivo de combinar diferentes medidas de qualidade de cursos de graduação e algumas variáveis de insumo em uma única medida. Ele é composto por oito componentes agrupados em três dimensões: a) desempenho dos estudantes, b) corpo docente, c) percepção dos discentes sobre as condições oferecidas para o desenvolvimento do processo formativo. $\mathrm{O}$ desempenho dos estudantes é avaliado através das notas do ENADE dos alunos concluintes e dos valores do Indicador da Diferença entre os Desempenhos Observado e Esperado (IDD). O corpo docente é avaliado com base em informações obtidas a partir do Censo da Educação Superior sobre a titulação e o regime de trabalho dos docentes vinculados aos cursos avaliados. Já a percepção discente sobre as condições do processo formativo é obtida por meio das respostas do questionário socioeconômico do ENADE e avalia a organização didático-pedagógica, a infraestrutura e instalações físicas e oportunidades de ampliação da formação acadêmica e profissional (INEP, 2017). Todas as medidas originais utilizadas para o cálculo do CPC são padronizadas e reescalonadas na forma de variável contínua, assumindo valores de 0 a 5 . Mais detalhes sobre o cálculo do CPC podem ser acessados na Nota Técnica $n^{\circ} 3 / 2017$. 
Ainda que o SINAES tenha sido elaborado com a ideia de que nota que é transformada, posteriormente, em rankings não é a melhor maneira para indicar a qualidade de um curso, os rankings permanecem desde o primeiro "provão" (BRITO, 2008). Essa prática foi incentivada a partir da criação do IGC e do CPC (BARREYRO, 2008). Como o IGC tem sido utilizado pelas instituições de ensino superior como sinônimo de qualidade geral da instituição, espera-se que com a divulgação das notas de IGC as IES consigam melhorar seu desempenho ao longo do tempo e a adequação às Diretrizes Curriculares de cada curso. Diante disso, uma das hipóteses desta pesquisa é que $\left(\mathrm{H}_{1}\right)$ o IGC apresentará um aumento significativo após a sua primeira divulgação.

Além disso, tomando por base a maneira como o IGC é calculado espera-se que $\left(\mathrm{H}_{2}\right)$ as universidades apresentem IGC superior em relação aos centros universitários, $\left(\mathrm{H}_{3}\right)$ as universidades apresentem IGC superior em relação às faculdades e que $\left(\mathrm{H}_{4}\right)$ IES públicas apresentem IGC superior em relação às IES privadas.

\section{MÉTODO}

Esta pesquisa classifica-se como uma pesquisa exploratória e descritiva (GIL, 2010), de caráter quantitativo (VERGARA, 2008; MINAYO, 2011). Apoia-se em dados secundários (MALHOTRA, 2012) provenientes do MEC e INEP para responder aos objetivos propostos. Utilizou-se apenas dados secundários, pois as informações contidas nos sites do MEC e INEP em relação ao IGC eram suficientes para responder ao problema de pesquisa atual. Baseado em critérios de intencionalidade (VERGARA, 2008) definiu-se as IES do estado de Santa Catarina como foco de estudo. A busca realizada em fevereiro de 2017 localizou 112 IES ativas no estado de Santa Catarina. Dado o elevado número de IES percebe-se que o ensino superior é bastante representativo no estado.

Como o foco da pesquisa foi observar IES do estado de Santa Catarina o primeiro passo foi identificar quais são essas instituições. Para tanto, utilizou-se no sistema e-MEC a opção consulta avançada. No campo Busca marcou-se a opção Instituição de Ensino Superior; no campo UF selecionou-se o estado de Santa Catarina; em Categoria Administrativa selecionou-se todos os itens disponíveis (Pública Municipal, Pública Federal, Pública Estadual, Privada sem fins lucrativos, Privada com fins lucrativos e Especial) e Organização Acadêmica também marcou-se todos os itens disponíveis (Faculdade, Centro Universitário, Institutos Federais e Universidade); e em Situação escolheu-se as ativas. Os demais campos 
(nome ou sigla da instituição, município e índice) ficaram em branco, para não adicionar mais filtros a pesquisa. Esta busca resultou em 112 IES cadastradas como ativas no sistema eMEC.

Como o IGC mede a situação de todos os cursos das instituições e não um curso específico analisou-se o IGC de todas as IES resultantes da primeira busca. Com isso, o próximo passo foi buscar as informações referentes ao IGC de 2007 a 2014destas instituições no site do INEP na sessão educação superior. Conforme mencionado na sessão anterior, o IGC é um indicador de qualidade geral dos cursos das IES e foi implantado pelo MEC em 2008. Desta forma este artigo trabalha com uma série temporal dos primeiros oito anos do indicador. No período da coleta de dados o IGC do ano de 2015 não havia sido divulgado. Por ser uma série temporal de oito anos com 112 IES, houve variações no número de IES que possuíam índice IGC em cada ano $\left(\mathrm{N}_{2007}=46 ; \mathrm{N}_{2008}=58 ; \mathrm{N}_{2009}=72 ; \mathrm{N}_{2010}=73 ; \mathrm{N}_{2011}=70\right.$; $\mathrm{N}_{2012}=78 ; \mathrm{N}_{2013}=79 ; \mathrm{N}_{2014}=80$ ).

Os dados foram tratados quantitativamente com auxílio do software SPSS 20. Para os cálculos de significância utilizou-se o nível de confiança mínimo de $95 \%(\alpha=0,05)$. Sabe-se que o indicador escolhido não é o único componente do SINAES, mas sua utilização nesta pesquisa se justifica devido ao fato de que grande parte da mídia e das IES utilizam seus resultados como indicador de qualidade.

\section{RESULTADOS}

O IGC foi divulgado pela primeira vez, pelo INEP, em 2008 e a última avaliação divulgada no período da coleta de dados foi em 2014. Os resultados das Instituições são divulgados em forma de um indicador contínuo (valores de 0 a 500) e em conceitos (com faixas de 1 a 5). A partir dos dados coletados no site do INEP pode-se mapear a situação das IES de Santa Catarina em relação ao Índice Geral de Cursos (IGC). No ano de 2014, 63 IES possuíam conceito 3, o que corresponde a $56 \%$ do total. Das demais, $4 \%$ possuíam conceito 2 , $10 \%$ conceito 4 e 1\% o conceito 5. Das 112 IES de Santa Catarina, 29\% não possuíam conceito IGC em 2014, o que corresponde a 32 instituições. Como algumas IES não possuíam IGC em nenhum dos períodos da coleta, estas Instituições foram excluídas da análise. Portanto, das 112 IES ativas em Santa Catarina, 92 possuem IGC em pelo menos um ano do período da coleta e este foi o número máximo utilizado nas análises seguintes. 
A Figura 1 apresenta a evolução média do IGC contínuo desde sua primeira avaliação. Percebe-se que houve pouca alteração no período. Porém, é importante notar que desde a sua primeira divulgação o período de 2008, 2009 e 2010 corresponde aos anos em que as IES obtiveram, na média, as piores avaliações. A partir de 2011 as IES apresentam uma melhora constante no IGC contínuo. Contudo, como o indicador é expresso por categoria absoluta (de 0 a 5), a melhora observada no indicador contínuo não é percebida no indicador absoluto, pois nos oito anos analisados as IES permaneceram, em média, na mesma categoria, ou seja, com conceito 3 .

Figura1 IGC contínuo no período

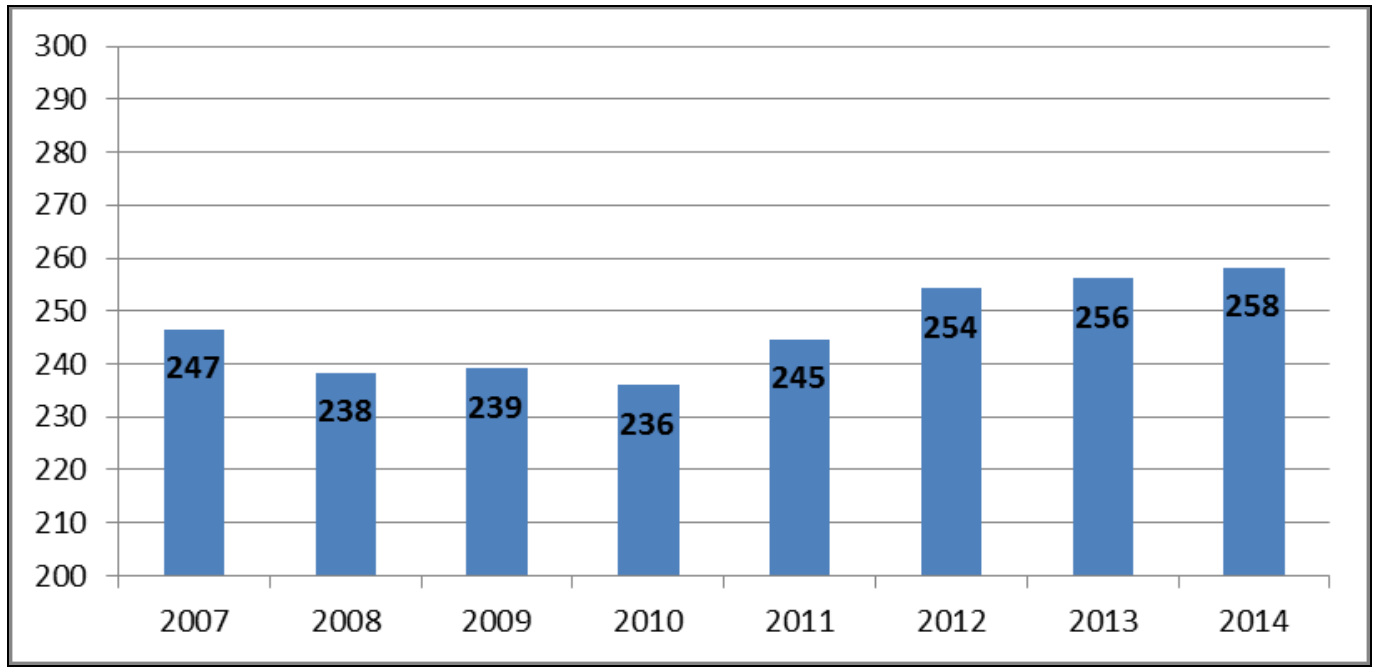

Fonte: Elaborado pelos autores.

Para analisar se a variação dos indicadores entre os anos é significativa realizou-se uma ANOVA de um fator com os dados do IGC contínuo do período. Primeiramente, verificou-se os pressupostos de normalidade e homogeneidade da distribuição. Ainda que todos os anos apresentem mais que 30 observações (n>30), o que nos leva a considerar a amostra como normal, o teste de Kolmogorov-Smirnov comprovou que todos os anos apresentam distribuição normal (todos com $\mathrm{p}>0,05$ ). $O$ teste de Levene indicou que as variâncias são homogêneas $(\mathrm{p}>0,05)$. Porém, como os grupos são desiguais no tamanho utilizou-se o teste de Welch para controlar esta desigualdade. Na Tabela 1 percebe-se que o teste de Welch foi marginalmente significativo na avaliação da evolução dos indicadores entre os anos analisados. Portanto, aceita-se a $\mathrm{H}_{1}$ desta pesquisa. 
Tabela 1: Teste Welch de comparação entre médias

\begin{tabular}{ccccc}
\hline & Statistic $^{\mathrm{a}}$ & $\mathrm{df1}$ & $\mathrm{df2}$ & Sig. \\
\hline Welch & 2,000 & 7 & 225,119 &, 056 \\
\hline
\end{tabular}

a. Asymptotically F distributed.

Fonte: Elaborado pelos autores

A análise geral do IGC identifica como o índice evoluiu nos últimos oito anos entre todas as instituições. É importante, também, identificarmos como o índice evoluiu em cada tipo de organização acadêmica cadastrada no MEC. Como citado, o IGC é calculado a partir do CPC que é dividido em três dimensões: desempenho dos estudantes (avaliado através da nota no ENADE e IDD), estrutura do corpo docente (titulação e regime de trabalho) e percepção dos discentes sobre as condições oferecidas para o desenvolvimento do processo formativo (organização didático-pedagógica, infraestrutura e instalações físicas, oportunidades de ampliação da formação acadêmica e profissional). Desta forma, de acordo com a $\mathrm{H}_{2}$ e $\mathrm{H}_{3}$ espera-se que as universidades apresentem desempenho superior em relação aos centros universitários e faculdades. A Figura 2 apresenta a média geral do IGC em cada ano, para cada tipo de organização acadêmica.

Figura 2 Evolução do IGC contínuo por tipo de Organização Acadêmica

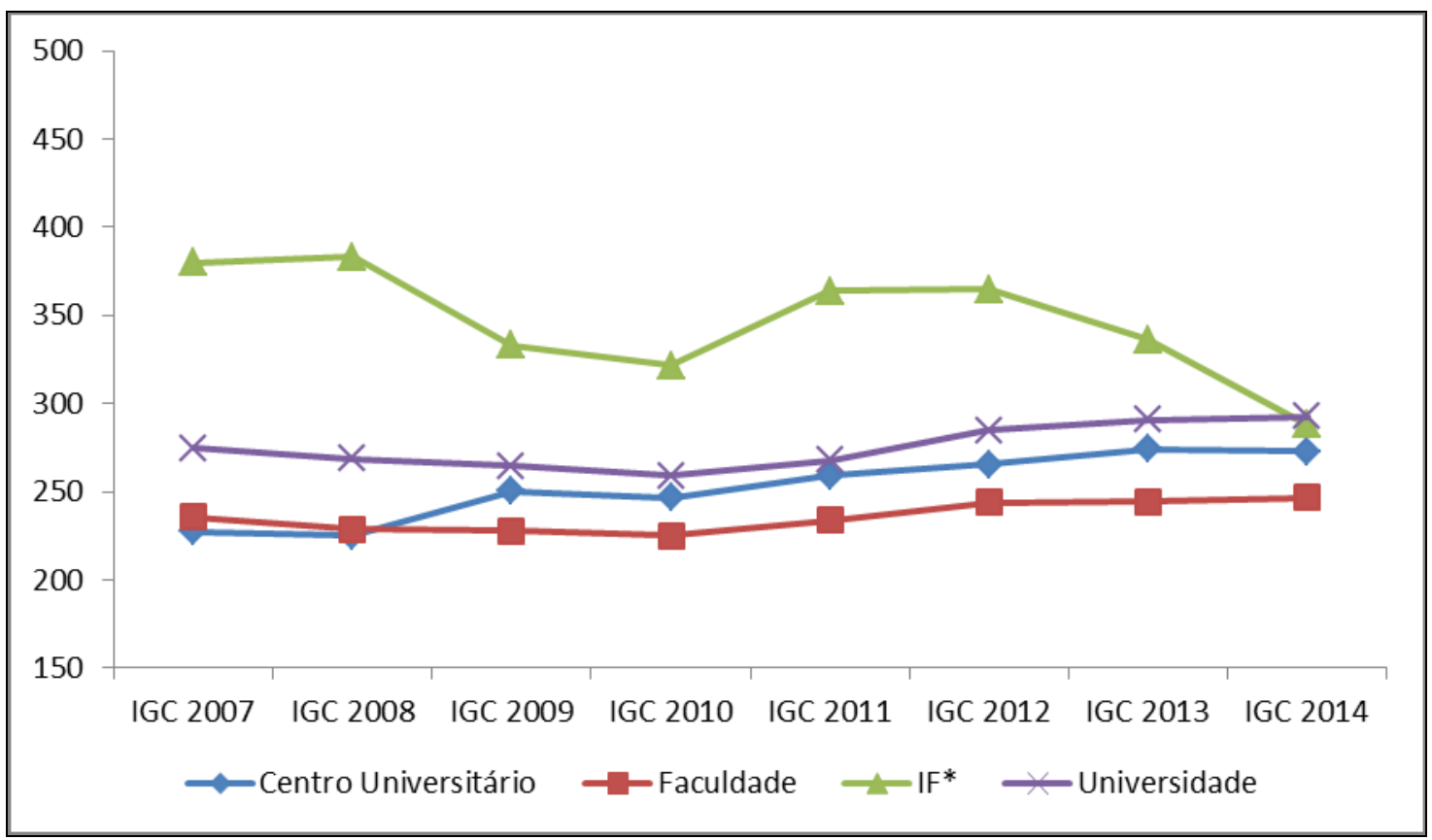

Fonte: Elaborado pelos autores 
Percebe-se que universidades, centros universitários e faculdades não tiveram uma oscilação muito grande no período, diferente dos institutos federais. A grande variação percebida no IGC dos IFs se dá em virtude de o estado de Santa Catarina possuir apenas dois IFs, sendo que em alguns anos apenas um teve avaliação. Desta forma, os resultados para este tipo de organização acadêmica ficam distorcidos. É importante destacar que a partir de 2010 as universidades, faculdades e os centros universitários apresentam uma melhoria contínua no IGC. Porém, as faculdades apresentam uma evolução mais lenta. A Figura 2 permite perceber que as universidades possuem qualidade superior, quando esta é medida pelo IGC. Para testar as hipóteses 2 e 3 realizou-se o teste de Kruskal Wallis. O teste de Kruskal Wallis é um teste não paramétrico de comparação de médias indicado para amostras pequenas $(n<30)$. Como os dados dos centros universitários e das universidades possuem amostra pequena optou-se por realizar um teste não paramétrico. Os Institutos Federais foram excluídos desta análise, pois conforme mencionado anteriormente, estes dados apresentam bastante variação e há apenas dois IFs no estado de Santa Catarina, o que distorceria a análise. A Tabela 2 apresenta o resultado do teste Kruskal Wallis para cada ano avaliado.

Tabela 2 Comparação do IGC por Organização Acadêmica

\begin{tabular}{l|c|c|c|c|c|c|c|c}
\hline & IGC & IGC & IGC & IGC & IGC & IGC & IGC & IGC \\
& $\mathbf{2 0 0 7}$ & $\mathbf{2 0 0 8}$ & $\mathbf{2 0 0 9}$ & $\mathbf{2 0 1 0}$ & $\mathbf{2 0 1 1}$ & $\mathbf{2 0 1 2}$ & $\mathbf{2 0 1 3}$ & $\mathbf{2 0 1 4}$ \\
\hline Chi-Square & 6,314 & 5,246 & 3,288 & 2,431 & 3,797 & 5,553 & 8,621 & 8,662 \\
Df & 2 & 2 & 2 & 2 & 2 & 2 & 2 & 2 \\
Asymp. &, $043^{*}$ &, $073 * *$ &, 193 &, 297 &, 150 &, $062 * *$ &, $013^{*}$ &, $013^{*}$ \\
Sig. & & &
\end{tabular}

${ }^{*} \mathrm{p}<0,05 ; * * \mathrm{p}<0,10$

Fonte: Elaborado pelos autores

Percebe-se que apenas nos anos 2007, 2013 e 2014 houve diferença estatisticamente significativa $(p<0,05)$ no IGC entre os tipos de organização acadêmica. Nos anos de 2008 e 2012 a diferença foi marginalmente significativa $(p<0,10)$. Para descobrir entre quais tipos de organização acadêmica há diferença significativa realizou-se o teste post hoc não paramétrico de Dunn, o qual compara dois grupos cada vez e é o teste post hoc indicado após rejeitar a hipótese nula pelo teste não paramétrico de Kruskall Wallis.

No ano de 2007, houve diferença estatisticamente significativa entre os IGCs dos centros universitários e universidades $(p=0,04)$ e entre faculdades e universidades $(p=0,02)$. Não houve diferença estatisticamente significativa entre o IGC de centros universitários e faculdades $(p>0,05)$. Assim, pode-se afirmar que neste ano o IGC das universidades foi 
superior ao dos centros universitários e das faculdades. Em 2013 houve diferença estatisticamente significativa apenas entre o IGC das faculdades e universidades, sendo que as universidades apresentaram IGC superior $(p<0,01)$. Entre faculdades e centros universitários a diferença foi marginalmente significativa $(\mathrm{p}=0,07)$. Já no ano de 2014 houve diferença entre o IGC das universidades e faculdades $(p<0,01)$. Porém, entre os demais tipos de organização acadêmica não houve diferença estatisticamente significativa.

Portanto, dos oito anos analisados apenas em três houve diferença entre os IGCs das IES ao serem agrupadas por organização acadêmica e destes apenas em 2007 e 2013 as universidades tiveram IGC superior aos centros universitários e faculdades. Desta forma, as hipóteses 2 e 3 precisam ser analisadas ano a ano para verificar sua validade. De todo modo, percebeu-se que em três dos 8 anos analisados as universidades apresentaram desempenho superior às faculdades e em outros dois anos essa diferença foi marginalmente significativa.

Após analisar a evolução do IGC nos últimos oito anos avaliados, bem como sua distribuição por tipo de organização acadêmica, buscou-se investigar se há diferença no IGC entre as Categorias Administrativas abordadas nesta pesquisa - pública e privada, para testar a hipótese 4. Espera-se que IES públicas apresentem um IGC mais elevado, pois o sistema foi construído a partir do olhar das IES públicas.

Para testar a hipótese 4 realizou-se o teste não paramétrico de Mann-Whitney, pois há comparação de apenas dois grupos (IES pública vs. IES privada) e o grupo das IES públicas apresenta $\mathrm{n}<30$. Conforme mencionando anteriormente, os testes não-paramétricos apresentam um desempenho superior quando a amostra possui menos de 30 observações. A Tabela 3 apresenta os dados do IGC do período agrupado por Categoria Administrativa, com o teste de significância das médias.

A partir da Tabela 3 percebe-se que a média do IGC das IES públicas se manteve superior das IES privadas. $\mathrm{O}$ teste $\mathrm{U}$ das médias demonstra que a superioridade na qualidade do ensino superior das IES públicas é significativa $(\mathrm{p}<0,01)$ em todos os períodos analisados. Desta forma, é possível aceitar a hipótese 3, pois as IES públicas apresentaram IGC superior às IES privadas.

A Tabela 3 proporciona uma segunda análise. A partir das médias do IGC por IES públicas e privadas é possível atribuir o IGC por faixa para cada tipo de instituição. De acordo com as notas técnicas do MEC/INEP o IGC faixa 3 corresponde ao intervalo de 1,95 a 2,94 do IGC contínuo. Da mesma forma, o IGC faixa 4 corresponde ao intervalo 2,95 a 3,94 do 
IGC contínuo. Percebe-se que durante todo o período analisado as IES públicas se mantiveram com conceito 4, enquanto as IES privadas com conceito 3. Confirmando também no IGC faixa a maior qualidade das IES públicas, sustentando a hipótese 4.

Tabela 3 IGC por Categoria Administrativa

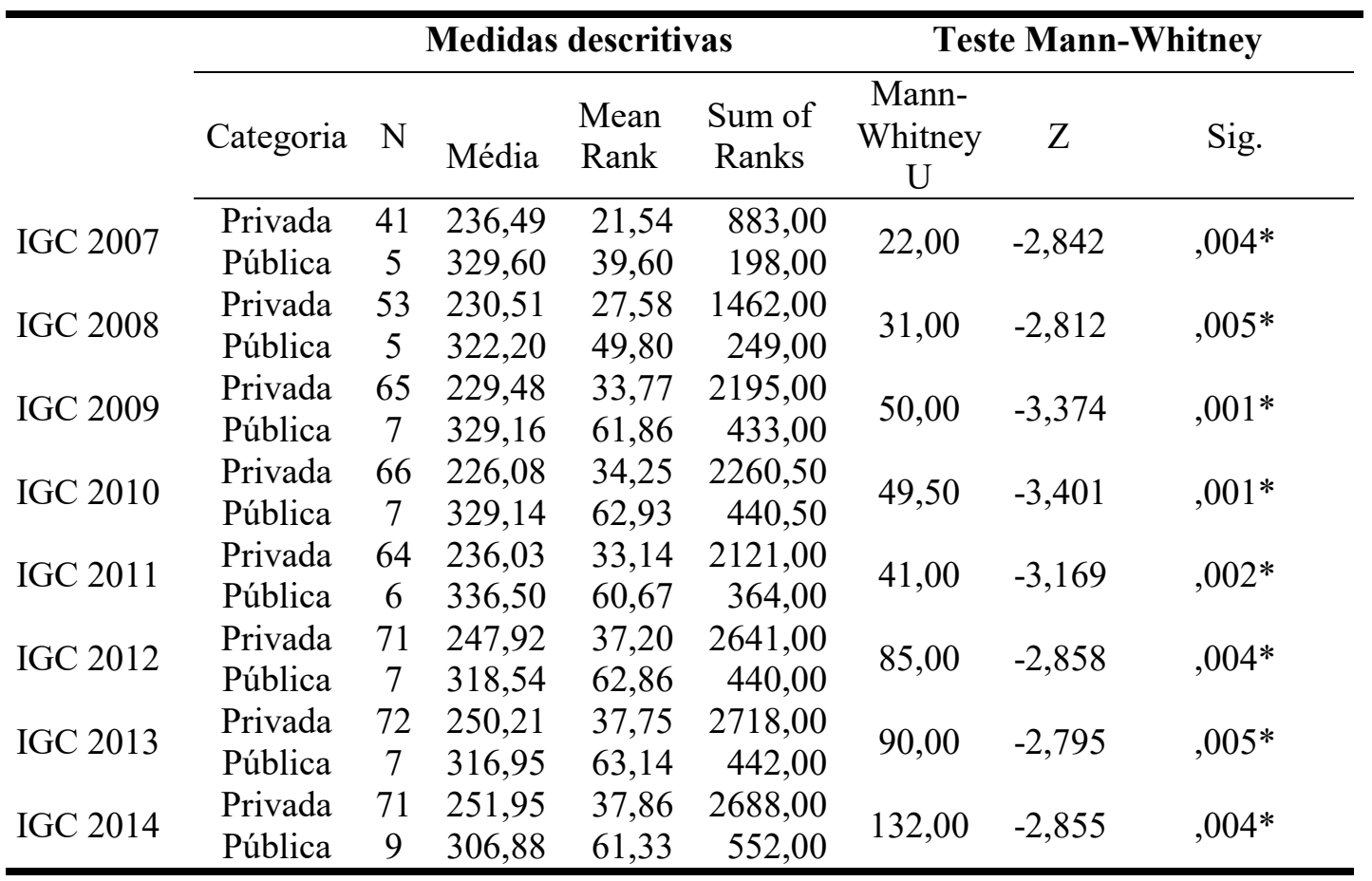

${ }^{*} \mathrm{p}<0,01$

Fonte: Elaborado pelos autores

Além de analisar cada período individualmente é necessário comparar em todo o período analisado para ver se a diferença se mantém significativa entre o IGC das IES públicas e privadas. Para isso, juntou-se o IGC de todos os períodos, agrupando-os por Categoria Administrativa. A partir disso, observa-se que os dois grupos apresentam mais do que 30 observações $(n>30)$, o que nos permite utilizar testes paramétricos para a análise. Desta forma, optou-se por realizar uma ANOVA e o teste de Welch para corrigir os resultados pela diferença nos tamanhos dos grupos. Os resultados demonstram que há diferença significativa no IGC das IES públicas e privadas, sendo que as públicas apresentam IGC superior $\mathrm{F}(1,554)=150,34, \mathrm{p}<0,001$. O teste de Welch que corrige a diferença no tamanho dos grupos também apresentou resultado significante $(\mathrm{p}<0,001)$. Assim, pode-se afirmar que no estado de Santa Catarina as IES públicas apresentam IGC superior em relação às IES privadas, sendo possível auferir que o desempenho das IES públicas é superior em relação às 
privadas, quando avaliadas pelos critérios do MEC, pois o IGC "sintetiza em um único indicador a qualidade de todos os cursos de graduação, mestrado e doutorado da mesma instituição de ensino" (MEC, 2018). Isso reforça a hipótese 4 desta pesquisa.

\section{CONSIDERAÇÕES FINAIS}

Ao final deste trabalho conclui-se que o IGC apresentou melhora marginalmente significativa no período analisado. A média geral do IGC sofreu pouca variação no período, mantendo-se em níveis inferiores nos anos de 2008, 2009 e 2010 com uma recuperação a partir de 2011. Porém, nos oito anos analisados as IES se mantiveram na faixa 3 em relação ao IGC absoluto.

Já ao analisar os tipos de organização acadêmica é possível notar que, na média, as universidades apresentaram um desempenho superior em relação às faculdades em três anos observados. Em relação às IES públicas e privadas, percebe-se que as primeiras possuem IGC maior. Isso leva a considerar que IES públicas possuem desempenho superior das demais instituições. Esse indicador de qualidade se manteve superior durante todo o período analisado. Entretanto, sugere-se novas pesquisas para investigar a participação relativa e a variação/evolução percentual dos dados relativos de universidades e faculdades na construção da nota do IGC.

É importante destacar que o IGC é composto por três dimensões, sendo que uma delas diz respeito a média dos CPCs do último triênio. Para o cálculo do CPC é levado em consideração o corpo docente da instituição. Sabe-se que, no geral, instituições públicas possuem corpo docente com titulação mais elevada e com regime de trabalho maior do que instituições privadas. Isso colabora para que o indicador IGC seja maior em instituições públicas. Como pesquisa futura sugere-se investigar se a diferença no indicador IGC entre instituições públicas e privadas está relacionada exclusivamente à dimensão corpo docente ou se outras dimensões, como uma nota de ENADE alta, refletem mais a superioridade do IGC.

Pesquisas futuras poderão avaliar, ainda, a qualidade das IES com apenas cursos à distância e tecnólogos, para verificar se há diferença entre estas modalidades. Pode-se comparar, também, a nota do IGC em relação à quantidade de cursos ofertados pela IES e a quantidade de alunos de cada curso. É possível que instituições com um número menor de curso ou com poucos alunos possam ter IGC maiores. Outra análise interessante é verificar como o IGC se comporta nos demais estados do Brasil, se no geral os indicadores apresentam 
melhora significativa ou se algum estado, individualmente, apresenta índices de qualidade melhores. Além disso, outros indicadores como a nota no ENADE podem ser avaliados e comparados com o IGC.

Da mesma forma, esta pesquisa pode ser complementada com uma análise qualitativa através de entrevistas com gestores de IES responsáveis pelas estratégias e decisões institucionais, com o objetivo de verificar se há esforço por parte da IES em melhorar estes indicadores; se estes indicadores são monitorados e qual a percepção da IES em relação aos indicadores do MEC.

Apesar de toda discussão ética e moral envolvendo os indicadores de qualidade, principalmente em relação a sua disposição em rankings, esta é a forma atual que o sistema avalia as instituições. Essas informações são usadas como estratégia para a conquista de novos alunos e parceiros e se transformam em importantes estratégias de mídia em prol da IES. Por isso, é necessária uma análise cuidadosa, por parte dos gestores de IES, de como índices traduzem a qualidade de sua instituição.

Sugere-se que os gestores de IES mantenham-se constantemente focados, monitorando os indicadores de qualidade do seu serviço. O indicador abordado nesta pesquisa não é o único responsável por atestar a qualidade de IES e cursos, pelo contrário, faz parte de um sistema maior e completo. Porém, uma análise detalhada deste indicador pode oferecer insights e direções aos gestores de IES, na busca de melhoria da qualidade e da imagem institucional, que se traduz em manutenção e expansão do mercado, visto que este é um dos principais indicadores abordados pela mídia ao publicar os rankings de Instituições Educacionais.

O modelo de avaliação atual recebe muitas críticas, principalmente no que diz respeito aos rankings publicados na mídia com as melhores instituições de ensino superior do país (BARREYRO, 2008; BRITO, 2008; LIMANA, 2008; POLIDORI, 2009). Entretanto, para Bittencourt (2009, p. 670) apesar das críticas "não há como prescindir de uma avaliação do aprendizado dos alunos por meio de exames ou provas em avaliações de larga escala", o que mostra que o SINAES é um modelo de avaliação em transformação e não um modelo definitivo (BARREYRO, 2008). Este trabalho segue a linha de estudos como o de Escobar, Dalfovo e Verdinelli (2010), Martínez e Silveira (2012), pois acredita-se que os indicadores são importantes para os gestores de IES e coordenadores de cursos, já que possibilita padrões de comparação e informações para tomada de decisão. 


\section{REFERÊNCIAS}

ALÉSSIO, Simone Cristina; DOMINGUES, Maria José Carvalho de Souza; SCARPIN, Jorge Eduardo. Fatores determinantes na escolha por uma Instituição de Ensino Superior do Sul do Brasil. VII Simpósio de Excelência em Gestão e Tecnologia - SEGeT, 2010.

BARREYRO, Gladys Beatriz. De exames, rankings e mídia. Avaliação (Campinas), v. 13. n. 3, p. 863-868, nov. 2008.

Do Provão ao SINAES. O processo de construção de um novo modelo de avaliação da educação superior. Avaliação (Campinas), v. 9. n. 2, p. 37-49, jun. 2004.

BASSO, Kenny; ANTONI, Verner Luis. Avaliação de cursos de graduação a partir da orientação para o mercado. Revista GUAL. Florianópolis, v. 6, n. 1, p. 212-232, jan. 2013.

BITTENCOURT, Hélio Radke; CASARTELLI, Alam de Oliveira; RODRIGUES, Alziro César de Morais. Sobre o índice geral de cursos (IGC). Avaliação (Campinas), v. 14, n. 3, p. 667-682, nov. 2009.

ALVES, Flávia Helena Dantes. Comunicação do posicionamento de marketing das instituições de ensino superior. 2009. 259f. Tese (Doutorado em Administração), Universidade de São Paulo, São Paulo, 2009.

BRITO, Márcia Regina F. de. O SINAES e o ENADE: da concepção à implantação. Avaliação (Campinas), v. 13, n. 3, p. 841-850, nov. 2008.

CRUZ, Breno de Paula Andrade; SPINOLA, Ana Teresa Schllaepfer; FREITAS JUNIOR, Antônio de Araújo. Estrutura curricular e ENADE: há uma correlação positiva e significativa entre o percentual de disciplinas quantitativas em um curso de administração e a nota do curso no ENADE? II Encontro de Ensino e Pesquisa em Administração e Contabilidade da ANPAD. Anais... Curitiba, PR: EnEPQ, 2009.

ESCOBAR, Maria Andréa Rocha; DALFOVO, Michael Samir; VERDINELLI, Miguel Angel Os índices IGC, ENADE e CAPES nos cursos de administração. Revista GUAL. Florianópolis, v. 3, n. 1, p. 1-14. 2010.

FRIGA, Paul N.; BETTIS, Richard A.; SULLIVAN, Robert S. Mudanças no ensino em administração: novas estratégias para o século XXI. Revista de Administração de Empresas. v. 44, n. 1, p. 96-115, 2004.

GIL, Antônio Carlos. Como elaborar projetos de pesquisa. 5a ed. São Paulo: Atlas, 2010.

GORDIANO; Ellen Campos Sousa; PEÑALOZA, Veronica; QUEZADO, Izabelle. Personalidade de marca de instituições de ensino superior: a percepção de alunos de uma faculdade privada e de uma universidade pública. Seminários em Administração. Anais... SEME $A D, 2012$. 
GRÖNROOS, Christian. Marketing: gerenciamento e serviços. Rio de Janeiro: Elsevier, 2009.

HARVEY, Lee; GREEN, Diana. Defining quality. Assessment and evaluation in higher education, Londres, v.18, n.1, p. 9-34, 1993.

INEP, Instituto Nacional de Estudos e Pesquisas Educacionais Anísio Teixeira. Disponível em $<$ http://portal.inep.gov.br/enade $>$ Acesso em janeiro de 2017.

LIMANA, Amir. desfazendo mitos: o que estão fazendo com o SINAES? Avaliação (Campinas), v. 13, n. 3, p. 869-873, nov. 2008.

LOURENÇO, Cléria Donizete da Silva; KNOP, Marcelo Ferreira Trezza. Ensino superior em administração e percepção da qualidade de serviços: uma aplicação da escala SERVQUAL. Revista Brasileira de Gestão de Negócios. São Paulo, v. 13, n. 39, p. 219-233, abr/jun. 2011.

MAINARDES, Emerson Wagner; DOMINGUES, Maria José Carvalho de Souza. Avaliação da qualidade de atributos específicos de instituições de ensino superior em cursos privados de administração em Joinville, SC. Organização \& Sociedade. Salvador, v.18 - n.58, p. 429444, Jul/Set. 2011.

MALHOTRA, Naresh K. Pesquisa de marketing: uma orientação aplicada. 4. ed. Porto Alegre: Bookman, 2012.

MARTÍNEZ, Mirna Susana Vieira; SILVEIRA, Marilene Vaz. Marcos regulatórios na educação superior: a gestão da Universidade da Região da Campanha - URCAMP frente às exigências legais. Revista GUAL. Florianópolis, v. 5, n. 1, p. 172-183, jan./fev./mar./abr. 2012.

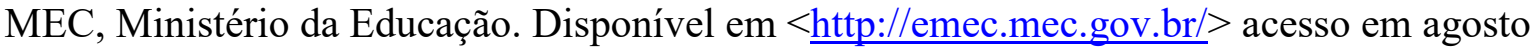
de 2018.

MYNAIO, Maria Cecília de Souza. (Org); DESLANDES, Suely Ferreira; GOMES, Romeu. Pesquisa Social: teoria, método e criatividade. 30 ed. Rio de Janeiro: Vozes, 2011.

PARASURAMAN, A.; ZEITHMAL, Valarie; BERRY, Leonard L. A conceptual model of service quality and its implications for future research. Journal of Marketing, p. 41-50, 1985.

SERVQUAL: a multiple-item scale for measuring consumer perceptions of service quality. Journal of Retailing, vol. 64, p. 12-40, 1988.

POLIDORI, Marlis Morosini. Políticas de avaliação da educação superior brasileira: provão, SINAES, IDD, CPC, IGC e...outros índices. Avaliação (Campinas), v. 14, n. 2, p. 267-290, jul. 2009. 
SILVA, Bruno César Linhares da Costa; SOUZA, Isadora Rebeca Andrade de; VASCONCELOS, Natália Veloso Caldas; QUEIROZ, Jamerson Viegas; QUEIROZ, Fernanda Cristina; ANDRADE, Dalliane Vanessa Pires. Análise da relação do IGC com o nível de integração virtual nas IES de melhor desempenho no Brasil. Revista GUAL. Florianópolis, v. 5, n. 1, p. 48-65, jan./fev./mar./abr. 2012.

SOARES, Francisco Luiz Batista; MILAN, Gabriel Sperandio. Fatores de Decisão que Influenciam a Escolha no Ensino Superior. Seminários em Administração. Anais... SEMEAD, 2008 .

SOBRINHO, José Dias. Qualidade, Avaliação: do SINAES a Índices. Avaliação (Campinas). v. 13, n.3, p. 817-825, nov. 2008.

TOMASSINI, Rodrigo; AQUINO, Rodrigo; CARVALHO, Frederico A. de. Expectativas e percepções em sequências de serviço. RAE- eletrônica. v. 7, n. 2, jul./dez. 2008.

TURETA, César; ROSA, Alexandre Reis; OLIVEIRA, Virgílio César da Silva e. Avaliação crítica de serviços educacionais: o emprego do modelo SERVQUAL. REGE Revista de Gestão USP, São Paulo, v. 14, n.4, p.33-45, out/dez, 2007.

VERGARA, Sylvia Constant. Métodos de Pesquisa em Administração. 3ed. São Paulo: Atlas, 2008.

VERINI, Robert E. Avaliação e regulação da educação superior: uma análise a partir dos primeiros 10 anos do SINAES. Avaliação (Campinas). v. 20, n.3, p. 603-619, nov. 2015. 